\title{
Atherosclerosis and Cardiovascular Disease in Rheumatoid Arthritis
}

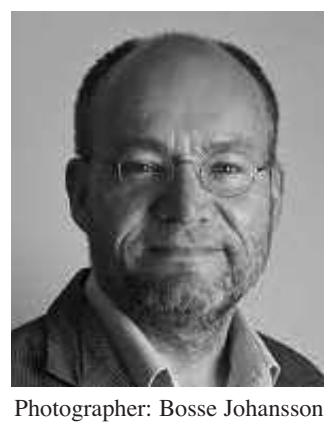

Photographer: Bosse Johansson
Atherosclerosis is an inflammatory disease, and the major cause of cardiovascular disease (CVD). This notion is based on the presence of immune-competent cells in atherosclerotic lesions in the intima of some arteries. Many of these cells - monocytes/macrophages, $\mathrm{T}$ cells, some mast cells, and even a few B cells and neutrophils - are activated, producing mainly proinflammatory cytokines ${ }^{1,2}$. Of note, atherosclerosis per se is not believed to be the major cause of CVD, even though arterial narrowing can play a role. Instead, it is complications of atherosclerosis leading to rupture of atherosclerotic plaques that appear to be the main underlying factor, causing atherothrombosis as manifested by myocardial infarction (MI) and stroke ${ }^{2}$.

Similarities between atherosclerosis and autoimmune diseases are indicated by studies in which adoptive transfer of $\beta_{2}$-glycoprotein I-reactive lymphocytes increases atherosclerosis in mouse models of atheroscleroses ${ }^{3}$. Further, the immune system can influence atherosclerosis development: immunization with heat shock protein $60 / 65$ increases atherosclerosis ${ }^{4}$, while the opposite is the case if oxidized low-density lipoprotein is used ${ }^{5}$.

It is interesting that the connection between inflammation and atherosclerosis was reported more than a century and a half ago by the Austrian pathologist Karl von Rokitansky, who described what can be inferred as inflammatory changes in atherosclerosis. This was also noted by the famous German pathologist Rudolf Virchow, who was also a pioneer in social medicine. These researchers had somewhat differing opinions about the nature of the disease. While Rokitansky thought the inflammation was secondary, Virchow believed it was mainly primary ${ }^{6}$. Both appear to have been right, because inflammation is a major characteristic of atherosclerosis per $s e^{2}$, while rheumatic inflammatory diseases confer increased risk of both atherosclerosis and $\mathrm{CVD}^{7,8}$. Thus, the increased risk of atherosclerosis and CVD in rheumatic disease is not only a clinical problem. Studies of these associations could also raise the understanding of the conditions themselves.

In systemic lupus erythematosus (SLE), the risk of CVD is higher, even 50 times higher, according to one study ${ }^{9}$. A combination of traditional and nontraditional risk factors appear to account for the raised risk of CVD in $\mathrm{SLE}^{7,10}$. Further, atherosclerosis, at least in the form of atherosclerotic plaques, is increased in several studies. In SLE, carotid intima-media thickness (cIMT) in general is not raised in some studies ${ }^{7,10}$. Other measures of atherosclerosis, such as the prevalence of echolucent plaques (reported to be more vulnerable), are raised in SLE ${ }^{11}$. Alternative measures besides cIMT should thus be investigated in rheumatic diseases such as SLE.

The situation appears to be less clear in rheumatoid arthritis (RA) than in SLE. While the risk of CVD is raised in many studies ${ }^{12}$, the increase is not as high as in SLE. Some authors have reported increased risk comparable to diabetes type $2^{13}$, but there are differences in results depending on stage of disease and other factors. Evidence indicates that, as in SLE, traditional risk factors such as dyslipidemia, hypertension, diabetes, and smoking play a role. In addition, nontraditional risk factors add to the risk burden ${ }^{7}$. We recently reported that antibodies against phosphorylcholine (anti-PC) could be of importance as independent protection markers in atherosclerosis and CVD in the general population. Mechanisms include antiinflammatory properties and decreased uptake of oxidized lipoproteins in the arterial wall. In SLE, antiphospholipid antibodies and low anti-PC levels ${ }^{7}$ are examples of nontraditional risk markers, while low anti-PC is a risk marker also in RA for atherosclerosis, CVD, and being a nonresponder to biologics ${ }^{14,15,16}$.

Another problem, especially in RA (and potentially many other inflammatory conditions), is the use of nonsteroidal antiinflammatory drugs (NSAID), which is so common that it is very difficult to control for. NSAID in general, not only cyclooxygenase- 2 inhibitors, are associated with increased risk of CVD, which is most likely related to thrombosis, although the effects on atherosclerosis development are little known ${ }^{17}$. It is not clear how large a part of the increased risk of CVD in RA could be

See Different type of carotid arterial wall remodeling in RA, page 2261

Personal non-commercial use only. The Journal of Rheumatology Copyright $\odot$ 2012. All rights reserved. 
attributed to NSAID use. Therefore detailed studies of the properties of arteries and atherosclerosis in RA are very important, because it is most likely (although not certain) that NSAID mainly act by influencing thrombosis risk ${ }^{17}$.

In this issue of the Journal of Rheumatology, van Sijl, et $a l^{18}$ report that patients with RA differ from healthy controls in carotid arterial wall remodeling, which is believed to be a response to hemodynamic and/or metabolic factors. This remodeling may be maladaptive if stress on the arterial wall increases too much ${ }^{19,20}$. Maladaptive outward modeling is also prospectively associated with clustering of risk factors $^{21}$ and may be related to plaque vulnerability ${ }^{22}$. There was no difference in cIMT between patients with RA and controls. However, measures of vascular remodeling such as circumferential wall stress and circumferential wall tension were calculated. The authors conclude that RA is associated with maladaptive outward carotid arterial remodeling, which could enhance the risk of CVD in RA even though cIMT was not raised.

This finding adds to the knowledge of atherosclerosis in rheumatic disease, and could contribute to our understanding of how CVD could ensue even though cIMT is not increased.

Further studies are needed to shed more light on the detailed properties of atherosclerosis and mechanisms and risk factors in plaque rupture in rheumatic diseases to improve prevention and treatment.

\section{JOHAN FROSTEGÅRD, MD, PHD,}

Professor of Medicine, Rheumatologist,

IMM, Karolinska Institutet,

Stockholm 17177, Sweden

Address correspondence to Dr. Frostegård;

E-mail: johan.frostegard@ki.se

\section{REFERENCES}

1. Frostegard J, Ulfgren AK, Nyberg P, Hedin U, Swedenborg J, Andersson U, et al. Cytokine expression in advanced human atherosclerotic plaques: Dominance of pro-inflammatory (Th1) and macrophage-stimulating cytokines. Atherosclerosis 1999;145:33-43.

2. Libby P, Ridker PM, Hansson GK. Progress and challenges in translating the biology of atherosclerosis. Nature 2011;473:317-25.

3. George J, Harats D, Gilburd B, Afek A, Shaish A, Kopolovic J, et al. Adoptive transfer of beta(2)-glycoprotein I-reactive lymphocytes enhances early atherosclerosis in LDL receptor-deficient mice. Circulation 2000;102:1822-7.

4. Xu Q, Dietrich H, Steiner HJ, Gown AM, Schoel B, Mikuz G, et al. Induction of arteriosclerosis in normocholesterolemic rabbits by immunization with heat shock protein 65 . Arterioscler Thromb 1992;12:789-99.

5. Palinski W, Miller E, Witztum JL. Immunization of low density lipoprotein (LDL) receptor-deficient rabbits with homologous malondialdehyde-modified LDL reduces atherogenesis. Proc Natl Acad Sci USA 1995;92:821-5.

6. Mayerl C, Lukasser M, Sedivy R, Niederegger H, Seiler R, Wick G. Atherosclerosis research from past to present - On the track of two pathologists with opposing views, Carl von Rokitansky and Rudolf Virchow. Virchows Arch 2006;449:96-103.

7. Frostegard J. Cardiovascular co-morbidity in patients with rheumatic diseases. Arthritis Res Ther 2011;13:225.
8. Tyrrell PN, Beyene J, Feldman BM, McCrindle BW, Silverman ED, Bradley TJ. Rheumatic disease and carotid intima-media thickness: A systematic review and meta-analysis. Arterioscler Thromb Vasc Biol 2010;30:1014-26.

9. Manzi S, Meilahn EN, Rairie JE, Conte CG, Medsger TA Jr, Jansen-McWilliams L, et al. Age-specific incidence rates of myocardial infarction and angina in women with systemic lupus erythematosus: Comparison with the Framingham Study. Am J Epidemiol 1997;145:408-15.

10. Svenungsson E, Jensen-Urstad K, Heimburger M, Silveira A, Hamsten A, de Faire U, et al. Risk factors for cardiovascular disease in systemic lupus erythematosus. Circulation 2001;104:1887-93.

11. Anania C, Gustafsson T, Hua X, Su J, Vikstrom M, de Faire U, et al. Increased prevalence of vulnerable atherosclerotic plaques and low levels of natural IgM antibodies against phosphorylcholine in patients with systemic lupus erythematosus. Arthritis Res Ther 2010;12:R214.

12. Meune C, Touze E, Trinquart L, Allanore Y. Trends in cardiovascular mortality in patients with rheumatoid arthritis over 50 years: A systematic review and meta-analysis of cohort studies. Rheumatology 2009;48:1309-13.

13. Peters MJ, van Halm VP, Voskuyl AE, Smulders YM, Boers M, Lems WF, et al. Does rheumatoid arthritis equal diabetes mellitus as an independent risk factor for cardiovascular disease? A prospective study. Arthritis Rheum 2009;61:1571-9.

14. Ajeganova S, Ehrnfelt C, Alizadeh R, Rohani M, Jogestrand T, Hafström I, et al. Longitudinal levels of apolipoproteins and antibodies against phosphorylcholine are independently associated with carotid artery atherosclerosis 5 years after rheumatoid arthritis onset - A prospective cohort study. Rheumatology 2011; 50:1785-93.

15. Ajeganova S, de Faire U, Jogestrand T, Frostegård J, Hafström I. Carotid atherosclerosis, disease measures, oxidized low-density lipoproteins, and atheroprotective natural antibodies for cardiovascular disease in early rheumatoid arthritis - An inception cohort study. J Rheumatol 2012;39:1146-54.

16. Ajeganova S, Fiskesund R, de Faire U, Hafstrom I, Frostegard J. Effect of biological therapy on levels of atheroprotective antibodies against phosphorylcholine and apolipoproteins in rheumatoid arthritis - A one year study. Clin Exp Rheumatol 2011;29:942-50.

17. Garcia Rodriguez LA, Gonzalez-Perez A, Bueno H, Hwa J. NSAID use selectively increases the risk of non-fatal myocardial infarction: A systematic review of randomised trials and observational studies. PLoS One 2011;6:e16780.

18. Van Sijl A, van den Hurk K, Peters M, van Halm V, Nijpels G, Stehouwer C, et al. Different type of carotid arterial wall remodeling in rheumatoid arthritis compared with healthy subjects: A case-control study. J Rheumatol 2012;39:2261-6.

19. Pasterkamp G, de Kleijn DP, Borst C. Arterial remodeling in atherosclerosis, restenosis and after alteration of blood flow: Potential mechanisms and clinical implications. Cardiovasc Res 2000; $45: 843-52$.

20. Glagov S, Weisenberg E, Zarins CK, Stankunavicius R, Kolettis GJ Compensatory enlargement of human atherosclerotic coronary arteries. N Engl J Med 1987;316:1371-5.

21. Ferreira I, Beijers HJ, Schouten F, Smulders YM, Twisk JW, Stehouwer CD. Clustering of metabolic syndrome traits is associated with maladaptive carotid remodeling and stiffening: A 6-year longitudinal study. Hypertension 2012;60:542-9.

22. Papafaklis MI, Koskinas KC, Chatzizisis YS, Stone PH, Feldman CL. In-vivo assessment of the natural history of coronary atherosclerosis: Vascular remodeling and endothelial shear stress determine the complexity of atherosclerotic disease progression. Curr Opin Cardiol 2010;25:627-38.

J Rheumatol 2012;39:2233-4; doi:10.3899/jrheum.121153

Personal non-commercial use only. The Journal of Rheumatology Copyright @ ${ }^{2012}$. All rights reserved. 